\title{
The Effect of Bariatric Surgery on Liver Histology
}

\author{
Rogier De Ridder · Erik Schoon • Ger Koek
}

Received: 16 February 2006 / Accepted: 28 March 2006 / Published online: 7 April 2007

(C) Springer Science+Business Media, Inc. 2007

\section{To the Editor:}

We read with interest the article by Jaskiewicz et al. in the January issue of this journal [1] about nonalcoholic fatty liver disease (NAFLD) treated by gastroplasty. The authors present a study on the prevalence of NAFLD in patients who underwent bariatric surgery and the effect on liver histology in a subset of patients. This subset of 10 patients is, to us, one of the most interesting parts of the study. The authors state that in all 10 patients the grade of hepatic inflammation improved after bariatric surgery, from at least moderate steatosis to mild steatosis. But information on the grade of fibrosis in these 10 patients before and after surgery is not given. Data on the effect of bariatric surgery on fibrosis are conflicting; Mattar et al. described the disappearance of any stage of fibrosis in $37 \%$ of patients after 15 months of followup [2]. However, Kral et al. showed, after a follow-up of 41 months, an increase in fibrosis stage in those patients with slight fibrosis prior to surgery [3].

R. De Ridder $(\bowtie) \cdot$ E. Schoon · G. Koek Department of Gastroenterology and Hepatology, University Hospital Maastricht, P.O. Box 5800, Maastrict 6221VA, the Netherlands e-mail: rdri@sint.azm.nl
In only $16 \%$ of the patients mentioned in the study by Jaskiewicz et al., any stage of fibrosis was present. These differences might be atributed to the type of surgery, the time between biopsies, and the extent of weight loss.

If possible, will you inform us about the effect on liver histology according to the Brunt criteria in those patients with repeated biopsies, in particular, the effect on the stage of fibrosis. Any differences from the previous mentioned studies might be related to the short follow-up period, 8 months, and the restrictive type of operation in this study.

\section{References}

1. Jaskiewicz K, Raczynska S, Rzepko R, Sledziński Z (2006) Nonalcoholic fatty liver disease treated by gastroplasty. Dig Dis Sci $51: 21-26$

2. Mattar SG, Velcu LM, Rabinovitz M, et al. (2005) Surgically induced weight loss significantly improves nonalcoholic fatty liver disease and the metabolic syndrome. Ann Surg 242:610620

3. Kral JG, Thung SN, Biron S, et al. (2003) Effect of surgical treatment of the metabolic syndrome on liver fibrosis and cirrhosis. Surgery $135: 48-58$ 